\title{
EFFICACY OF MEDIUM CHAIN FATTY ACIDS AND SACCHAROMYCES CEREVISIAE ON GROWTH PERFORMANCE OF BROILER
}

\author{
M. S. Islam ${ }^{1}$, M. A. Islam ${ }^{2}$, M. S. Rahman ${ }^{1}$ and S. M. S. H. Belal ${ }^{3 *}$ \\ ${ }^{1}$ Department of Medicine, Surgery and obstetrics, Hajee Mohammad Danesh Science and Technology \\ University, Dinajpur, Bangladesh; ${ }^{2}$ Executive, Veterinary Services Department, Agrovet Division, Square \\ Pharmaceuticals Limited, Dhaka, Bangladesh; ${ }^{3}$ Veterinary Surgeon (Leave Reserve), Department of Livestock \\ Services, Dhaka, Bangladesh
}

\begin{abstract}
The study was conducted to determine the effect of medium chain fatty acids and Saccharomyces cerevisiae on performance in broiler birds. A field trial was carried out on 200 broiler chicks (Lohmann) dividing them into four treatment groups each having 50 birds such as treatment group $1\left(\mathrm{~T}_{1}\right)$, treatment group $2\left(\mathrm{~T}_{2}\right)$, treatment group $3\left(\mathrm{~T}_{3}\right)$, and a control group $(\mathrm{C})$. The treatment group $1\left(\mathrm{~T}_{1}\right)$ was supplied with a standard feed containing medium chain fatty acids (MCFA) and Saccharomyces cerevisiae (S. cerevisiae type boulardii $\left.2.0 \times 10^{10} \mathrm{CFU} / \mathrm{gm}\right)$. Treatment group $2\left(\mathrm{~T}_{2}\right)$ was supplied with a standard feed rich in medium chain fatty acids (MCFA). Treatment group 3 ( $\mathrm{T}_{3}$ ) was supplied with a standard feed having Saccharomyces cerevisiae (S. cerevisiae type boulardii 2.0x1010 CFU/gm). MCFA and S. cerevisiae lacked standard feed was given to the control group (C). The inclusion rate of MCFA per kilogram of feed was $2 \mathrm{gm}$ for 10 days, $1.5 \mathrm{gm}$ for successive 10 days and $1 \mathrm{gm}$ for next 8 days, and of Saccharomyces cerevisiae was $0.2 \mathrm{gm}$ for 10 days, $0.15 \mathrm{gm}$ for successive 10 days and $0.10 \mathrm{gm}$ for next 8 days during the study period of 4 weeks. Weekly weight gain and, at the end of the study, body weight, feed consumption, FCR and mortality rate were recorded. Analysis of data revealed that the final average body weight and average weight gain of the birds belonging to the groups $T_{1}, T_{2}$ and $T_{3}$ were higher $(p<0.01)$ than the control group. FCR was 1.36, 1.37, and 1.38 for the treatment group $\mathrm{T}_{1}, \mathrm{~T}_{3}$ and $\mathrm{T}_{2}$ respectively which were better than $(\mathrm{p}<0.05)$ control group. There was no significant difference between the treatment group $T_{2}$ and $T_{3}$ but there was significant difference between the treatment group and control group $(\mathrm{p}<0.10)$ in terms of feed consumption. In case of livability, there was significant difference among bird groups $T_{1}, T_{2}, T_{3}$ and control group $(\mathrm{p}<0.01)$. Data analyses regarding organ weight showed that the addition of MCFA and SC in the diet of treatment group one $\left(\mathrm{T}_{1}\right)$ significantly increased $(\mathrm{p}<0.01)$ the weight of intestine with chymus, intestine without chymus, gizzard, head and neck by $41 \%, 17 \%, 5 \%, 8 \%$ and $11 \%$ respectively compared with control group. No significant differences were observed among the experimental groups for the weight of liver, spleen, and pancreas.
\end{abstract}

Keywords: Medium chain fatty acid, yeast, performance, broiler

\section{INTRODUCTION}

The broiler production and consumption of meat is increasing rapidly. However, its profitability depends on the growth rate, improved FCR and gut health of the birds. Antibiotics are generally using for the elimination of intestinal bacteria, thereby enhancing growth rate and feed efficiency of the birds. The extensive use of antibiotics in birds has led to the development of antibiotic-resistant bacteria in the gastrointestinal tract and drug residuals in meat. So, some countries have banned inclusion of antibiotic as growth promoter in the ration. Alternative to the antibiotics, the use of probiotics in order for the competitive exclusion of the colonization of intestinal pathogens has been proposed for poultry. Probiotics are defined as viable microorganisms (bacteria or yeasts) that exhibit a beneficial effect on the health of the host when they are ingested (Khaksefidi and Rahimi, 2005).

New candidates having antimicrobial and growth promoting properties are the medium chain fatty acids (MCFA) and yeast (Saccharomyces cerevisiae, SC). Fatty acids with a chain length between 6 and 12 carbon atoms are regarded as Medium chain fatty acids (MCFA). Many experiments in vitro have confirmed the antimicrobial properties of MCFA against enteric pathogens such as Escherichia coli, Salmonella typhymurium, Campylobacter jejuni and Clostridium perfringens. Considering such antibacterial properties, MCFA are, among the candidates for new non-antibiotic feed additives, helpful in providing healthy gastrointestinal

*Corresponding e-mail address: shariful.belal@yahoo.com

Copyright (c) 2018 Bangladesh Society for Veterinary Medicine

All rights reserved 0408/2018 


\section{Islam and others}

condition in broilers. Based on research with poultry, MCFA can be an alternative to antibiotic growth promoters (Khosravinia, 2015).Yeast microbes are probably one of the earliest domesticated organisms. For a long time, yeast products have been successfully included in feed as natural growth promoters for animals and poultry. Yeasts are unicellular and most of them reproduce asexually by mitosis and many do so by an asymmetric division process called budding (Adebiyi et al., 2012).Various strains of Saccharomyces cerevisiae (SC) have long been fed to animals as a source of unknown growth factor. It was reported that feeding $S C$ to chickens improved weight gain and feed/gain ratio (Zhang et al., 2005). In addition to growth performance, there are literature (Akiba et al., 2001; Lee et al., 2002) showing that enrichment of diets with yeast could favorably improve broiler meat quality. Specifically, edible meats sampled from broiler chickens fed a diet containing $S C$ exhibited increased tenderness (Bonomi et al., 1999) and increased water-holding capacity (Lee et al., 2002). However, the effect of $S C$ supplementation on oxidative stability of chicken meat was not extensively studied although there are indications (Meyer et al., 1994; Ampel et al., 2000) that $S C$ may possess antioxidant property. Conducted research indicated that the commercialized types of yeast have the ability to optimize feed digestibility and utilization. However, little information has been published on the synergetic effects of medium chain fatty acids and Saccharomyces cerevisiae on performance in broiler chickens. So, this study was carried out to investigate the effect of dietary supplement of medium chain fatty acids (galibiotic ${ }^{\circledR}$ ) and Saccharomyces cerevisiaetype boulardii (CNCM 1-1079) $2.0 \times 10^{10} \mathrm{CFU} / \mathrm{gm}$ (Levucell SB $20 \mathrm{ME}$ Powder ${ }^{\circledR}$ ) and their combination on production performance, carcass characteristics and cost effective ratio of broiler production under Bangladesh condition.

\section{MATERIALS AND METHODS}

\section{Study area and period}

The research work was conducted in a poultry farm of Kishoreganj district of Bangladesh. The experimental work was in the form of four weeks feeding trial, carried out in the spring season during the period from $1^{\text {st }}$ March, 2017 to $28^{\text {th }}$ March, 2017 to assess the value of Medium chain Fatty acids and Saccharomyces cerevisiae type boulardii as growth and health promoter for broiler chicks.

\section{Experimental birds and management}

The experiment was carried out with 200 commercial broiler hybrid strain of day-old chicks (Lohmann) purchased from a commercial hatchery (Kazi Farms Group). The chicks were divided into 4 groups and reared on deep litter in separate compartments measuring 50 square feet each of the farm house (Figure 1). The compartments were thoroughly cleaned, white washed and disinfected before putting the experimental chick into these. Each group was named as the treatment group 1 (T1), treatment group 2 (T2), treatment group 3 (T3), and the control group (C). All the birds were provided with the same management conditions like floor space, temperature, relative humidity, ventilation and lighting. Immediately after unloading from the chick boxes the chicks were given glucose and vitamin-C to prevent the stress occurring during transportation. After 2 hours of arrival, chicks were offered to drink and feed on mash ration. Each pen was equipped with one flat chick feeding tray for the first few days, and then replaced by linear feeder and thereafter, round feeder (Figure 2). One round drinker was supplied in each pen, and one electric bulb of 60 watts was used for lighting and as a source of heat during brooding. Brooding temperature were maintain correctly. Optimum light was provided daily throughout the whole experimental period. The chicks were brooded at $95^{\circ} \mathrm{F}$ during first week and thereafter; the temperature was reduced by $5^{0} \mathrm{~F}$ every week until the temperature reached to the room temperature. The starter and finisher broiler rations were supplied to the broiler chicken appropriately. A weighed amount of the ration was offered to the birds twice a day and the left over feed was collected to calculate feed consumption of the birds.

\section{Experimental agents}

Commercially available medium chain fatty acids (galibiotic ${ }^{\circledR}$ ) and Saccharomyces cerevisiae type boulardii (CNCM 1-1079), 2.0x10 ${ }^{10} \mathrm{CFU} / \mathrm{gm}$ (Levucell SB 20 ME Powder ${ }^{\circledR}$ ) were used in this study. The products were of the Agrovet Division of the Square Pharmaceuticals Ltd., Dhaka, Bangladesh. 


\section{Feeding Management}

The experimental birds were feed on the starter feed for the first two weeks and were allowed to feed on the finisher feed for the rest of the life. Two commercially available experiential feed used in the experiment were chick starter and finisher. The feed were formulated by ZHENGBANG BAY (BD) LTD by using feed ingredients commonly used in poultry feeding in Bangladesh. The analyses of the feed are shown below (Table 1 and 2).

Table 1. Starter feed analyses

\begin{tabular}{c|c|c|c|c|c|c}
\hline $\mathrm{CP}$ & $\mathrm{ME}(\mathrm{kcal} / \mathrm{kg})$ & $\mathrm{CF}$ & $\mathrm{F}$ & $\mathrm{Ca}$ & $\mathrm{P}$ & $\mathrm{M}$ \\
\hline $22 \%$ & 3200 & $5 \%$ & $4 \%$ & $0.85 \%$ & $0.50 \%$ & $12 \%$ \\
\hline
\end{tabular}

Table 2. Finisher feed analyses

\begin{tabular}{c|c|c|c|c|c|c}
\hline $\mathrm{CP}$ & $\mathrm{ME}(\mathrm{kcal} / \mathrm{kg})$ & $\mathrm{CF}$ & $\mathrm{F}$ & $\mathrm{Ca}$ & $\mathrm{P}$ & $\mathrm{M}$ \\
\hline $20 \%$ & 3000 & $5 \%$ & $5 \%$ & $0.75 \%$ & $0.45 \%$ & $12 \%$ \\
\hline
\end{tabular}

Legends: $\mathrm{CP}=$ Crude Protein, $\mathrm{CF}=$ Crude Fiber, $\mathrm{F}=\mathrm{Fat}, \mathrm{Ca}=$ Calcium, $\mathrm{P}=$ Phosphorus, $\mathrm{M}=$ Moisture

The treatment group $1\left(\mathrm{~T}_{1}\right)$ received a standard feed with commercially available both medium chain fatty acids (MCFA) and Saccharomyces cerevisiae (S. cerevisiae type boulardii $\left.2.0 \times 10^{10} \mathrm{CFU} / \mathrm{gm}\right)$. The treatment group 2 $\left(\mathrm{T}_{2}\right)$ received standard feed with MCFA only. The treatment group $3\left(\mathrm{~T}_{3}\right)$ received standard feed with $S$. cerevisiae, and the control group (C) received standard feed only. The MCFA was supplemented at the rate of 2 $\mathrm{gm} / \mathrm{kg}$ feed for the first 10 days, $1.5 \mathrm{gm} / \mathrm{kg}$ feed for successive 10 days and $1 \mathrm{gm} / \mathrm{kg}$ feed for next 8 days and the Saccharomyces cerevisiae was given at the rate of $0.2 \mathrm{gm} / \mathrm{kg}$ feed for the first 10 days, $0.15 \mathrm{gm} / \mathrm{kg}$ feed for successive 10 days and $0.10 \mathrm{gm} / \mathrm{kg}$ feed for next 8 days during the whole experiment.

\section{Experimental Procedures}

On arrival, the chicks were unpacked in a holding pen inside the experimental house. They were visually inspected for health, thriftiness and weakness. Underweight and unhealthy chicks were excluded from the experiment. Two hundred chicks were then randomly assigned to the experimental pens at the rate of 50 chicks per pen. The birds in each pen were then weighed to determine their initial live weight, and were then offered the respective diet. Weekly feed consumption, live weight, weight gain, and mortality were recorded. At the end of each week, live weight of the experimental birds in each pen was determined and the weekly live weight gain was assessed by difference from that of the previous week. The live weight gain was then related to the weight of the feed consumed per week to calculate the feed conversion ratio, as grams feed consumed per week over the live weight gain in grams for the same week. They were then statistically analyzed for the treatment difference as per DMRT. At the end of the experiment, weights of different organs of the body were measured to find out the effect of medium chain fatty acids and Saccharomyces cerevisiae on organ -weights of broiler chickens.

\section{Experimental layout}

A total of 200 day- old broiler chicks randomly assigned into 4 dietary treatment groups were as follows:

Treatment group $\mathrm{T}_{1}(50)$ : Basal diet+ MCFA + Saccharomyces cerevisiae

Treatment group $\mathrm{T}_{2}$ (50): Basal diet+ MCFA

Treatment group $\mathrm{T}_{3}$ (50): Basal diet+ Saccharomyces cerevisiae

Control group C (50): Basal diet

\section{Vaccination schedule}

The birds were immunized against some commonly occurring diseases with commercially available and good reported vaccines as per schedule prescribed by the company (Table 3).

Table 3. Immunization schedule of the experimental birds with vaccines produced by ACI Animal Health

\begin{tabular}{lllll}
\hline Age (Day) & \multicolumn{1}{c|}{ Diseases } & Vaccine & Route \\
\hline $1^{\text {st }}$ day & Newcastle Disease+ Infectious Bronchitis & Cevac BIL & Eye drop \\
$9^{\text {th }}$ day & Infectious Bursal Disease & Cevac IBDL® & Through drinking water \\
$16^{\text {th }}$ day & Infectious Bursal Disease & Cevac IBDL® & Through drinking water \\
$21^{\text {st }}$ day & Newcastle Disease & Cevac NewL $®$ & Through drinking water \\
\hline
\end{tabular}




\section{Islam and others}

\section{RESULTS}

\section{Live weight}

The initial body weights in treatment group 1 (T1), treatment group 2 (T2), treatment group 3 (T3), and the control group (C) were $187.700 \mathrm{~g}, 185.388 \mathrm{~g}, 186.531 \mathrm{~g} \& 183.429$ respectively in first 14 days whereas, the final body weight in experimental birds were $1587.980 \mathrm{~g}, 1561.713 \mathrm{~g}, 1568.308 \mathrm{~g} \& 1444.832 \mathrm{~g}$ respectively in total 28 days of rearing. Initial live weights among the experimental groups were not significantly $(\mathrm{P}>0.05)$ different (Figure 1). Productive performance of broiler supplemented with medium chain fatty acids (galibiotic $\left({ }^{\circledR}\right)$ and Saccharomyces cerevisiae type boulardii (CNCM 1-1079) 2.0x1010 CFU/gm (Levucell SB 20 ME Powder®) and their combination showed final live weight significantly $(\mathrm{p}<0.01)$ higher in experimental birds of the group $T_{1}$, group $T_{3}$ and group $T_{2}$ as compared to the control group (C) up to 4 weeks of age (Table 4 and Figure 1).

Table 4. Effect of medium chain fatty acids (galibiotic ${ }^{\circledR}$ ) and Saccharomyces cerevisiae type boulardii (Levucell SB 20 ME Powder ${ }^{\circledR}$ ) on productive performances of different experimental dietary treatment groups of broilers

\begin{tabular}{|c|c|c|c|c|c|c|c|c|c|c|c|c|}
\hline \multirow[t]{2}{*}{ Parameters } & \multicolumn{2}{|c|}{$\begin{array}{l}\text { Initial B. W. } \\
\left(2^{\text {nd }} \text { weeks }\right)\end{array}$} & \multicolumn{2}{|c|}{$\begin{array}{l}\text { Final B. W. } \\
\left(4^{\text {th }} \text { weeks }\right)\end{array}$} & \multicolumn{2}{|c|}{$\begin{array}{l}\text { Weight gain }(\mathrm{g}) \\
\left(2^{\text {nd }}-4^{\text {th }} \text { weeks }\right)\end{array}$} & \multicolumn{2}{|c|}{$\begin{array}{l}\text { Feed consumption } \\
(\mathrm{g})\end{array}$} & \multicolumn{2}{|c|}{ FCR } & \multicolumn{2}{|c|}{ Livability (\%) } \\
\hline & Mean & SEM & Mean & SEM & Mean & SEM & Mean & SEM & Mean & SEM & Mean & SEM \\
\hline $\mathrm{MCFA}+\mathrm{SC}\left(\mathrm{T}_{1}\right)$ & 187.700 & 0.949 & $1587.980^{\mathrm{a}}$ & 0.632 & $1400.280^{\mathrm{a}}$ & 1.581 & $2169.632^{b}$ & 3.162 & $1.360^{\mathrm{b}}$ & 0.032 & $98^{\mathrm{a}}$ & 0.316 \\
\hline $\operatorname{MCFA}\left(\mathrm{T}_{2}\right)$ & 185.388 & 1.581 & $1561.713^{\mathrm{c}}$ & 3.162 & $1376.325^{\mathrm{b}}$ & 4.743 & $2164.409 b^{c}$ & 1.265 & $1.380^{\mathrm{b}}$ & 0.063 & $98^{\mathrm{a}}$ & 0.632 \\
\hline $\mathrm{SC}\left(\mathrm{T}_{3}\right)$ & 186.531 & 3.162 & $1568.308^{\mathrm{b}}$ & 0.632 & $1381.777^{\mathrm{b}}$ & 3.795 & $2160.980^{\mathrm{c}}$ & 1.581 & $1.370^{\mathrm{b}}$ & 0.032 & $98^{\mathrm{a}}$ & 0.316 \\
\hline Control ( C ) & 183.429 & 0.949 & $1444.832^{\mathrm{d}}$ & 1.265 & $1261.403^{\mathrm{c}}$ & 0.316 & $2175.832^{\mathrm{a}}$ & 1.581 & $1.500^{\mathrm{a}}$ & 0.095 & $96^{\mathrm{b}}$ & 0.316 \\
\hline $\mathrm{p}$ value & 0.451 & & 0.000 & & 0.000 & & 0.001 & & 0.041 & & 0.007 & \\
\hline Significance & NS & & $* *$ & & $* *$ & & $* *$ & & $*$ & & $* *$ & \\
\hline
\end{tabular}

$\mathrm{MCFA}=$ Medium chain fatty acids, $\mathrm{SC}=$ Saccharomyces cerevisiae, B.W. = Body weight, $\mathrm{FCR}=\mathrm{Feed}$ conversion ratio.

$*=$ Significant at $5 \%$ level of probability; $* *=$ Significant at $1 \%$ level of probability; NS = Not significant; SEM= Standard error of mean. In a column figures with same letter or without letter do not differ significantly whereas figures with dissimilar letter differ significantly (as per DM)

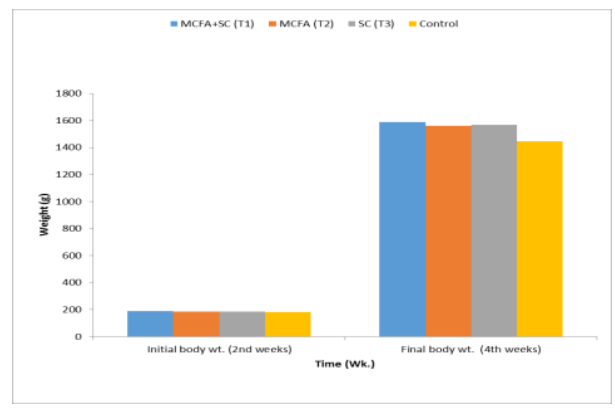

Figure 1. Average body weight trends of experimental birds

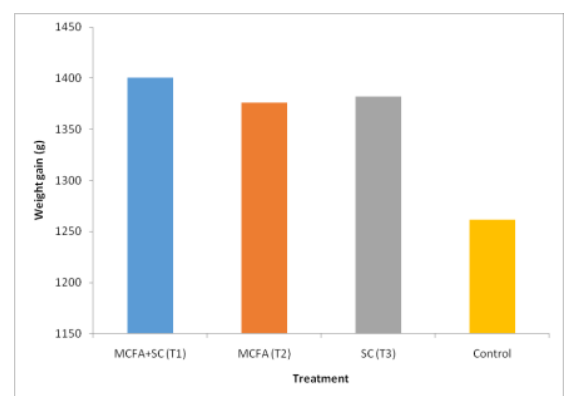

Figure 2. Average weight gain trends of experimental birds

\section{Live weight gain}

The results of the live weight gains were found significantly $(\mathrm{p}<0.01)$ higher in experimental birds of the group $T_{1}$, group $T_{3}$ and group $T_{2}$ as compared to the control group (C) up to $4^{\text {th }}$ weeks of age (Table 4 and Figure 2).

\section{Feed consumption}

The data present that, the dietary treatments did not have any significant effects on the mean total feed consumption of the experimental birds group $\mathrm{T}_{2}$ and $\mathrm{T}_{3}$. A general trend in total feed consumption is, however noticeable, showing that the highest feed consumption (2175.832 g/ birds) was attained by the control group (C), 
followed by the treatment group 1 (2169.632 g/birds) and treatment group 2 (2164.409g/birds). The lowest feed consumption $\left(2160.980 \mathrm{~g} /\right.$ birds) was attained by the treatment group three $\left(\mathrm{T}_{3}\right)$ (Table 4 and Figure 3 ).

\section{Feed conversion ratio $(\mathrm{FCR})$}

Table (4) also presents the data on feed conversion ratio. Treatment group $1\left(\mathrm{~T}_{1)}\right.$ fed the diet containing MCFA and SC attained the best feed conversion ratio (1.36), and it was followed by the treatment group 3 (1.37) fed on diet containing SC and treatment group 2 (1.38) fed on diet containing MCFA. Poor feed conversion ratio (1.50) was attained by the control group (C) of birds fed the standard diet only (Table 4 and Figure 4).

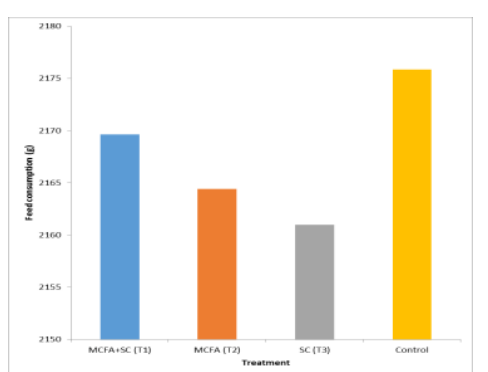

Figure 3. Feed consumption trends of experimental birds

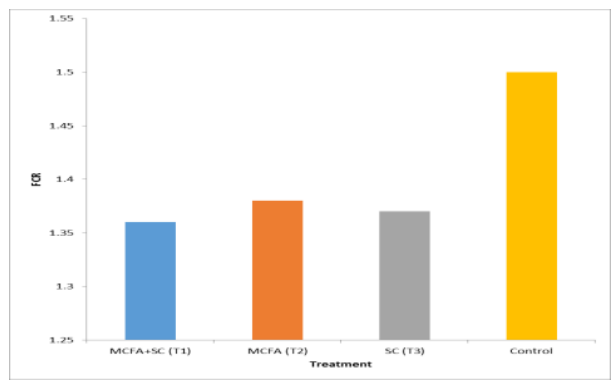

Figure 4. Feed conversion ratio (FCR) of experimental birds

\section{Livability}

Analysis showed that livability of the treatment groups 1, 2, and 3 was higher than the control group, but the livability among the treatment groups was not significant different (Table 4 and Figure 5).

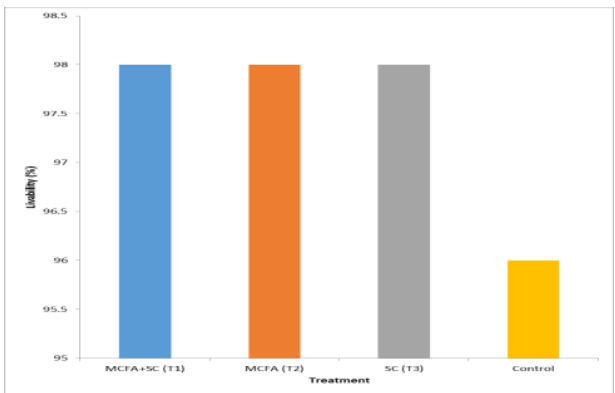

Figure 5. Livability percentage of experimental birds

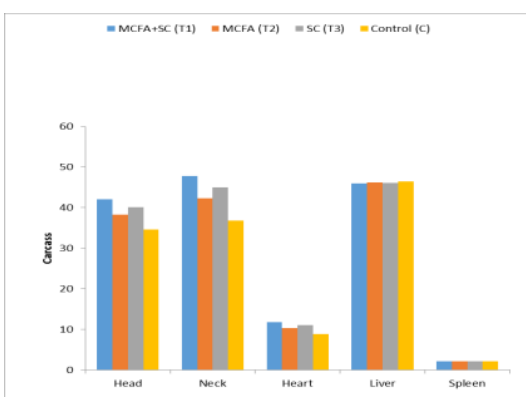

Figure 6. Carcass characteristics (Organ weights)

\section{Organ- weight}

The organ-wise data analysis reveals that, the dietary treatments have significant effects on the weights of head, neck, heart, proventriculus, gizzard, intestine with chymus and intestine without chymus $(\mathrm{P}<0.05$, Table 5). The highest weight of these parameters is noticeable in the group of birds fed the diet containing MCFA + SC, which was significantly higher than that of the birds fed on the other experimental diets (Table 5 and Figures 6, 7 \& 8)

Table 5. Effect of medium chain fatty acids and Saccharomyces cerevisiae on organ weights of broiler chickens

\begin{tabular}{|c|c|c|c|c|c|c|c|c|c|c|}
\hline & \multicolumn{2}{|c|}{ Head } & \multicolumn{2}{|c|}{ Neck } & \multicolumn{2}{|c|}{ Heart } & \multicolumn{2}{|c|}{ Liver } & \multicolumn{2}{|c|}{ Spleen } \\
\hline & Mean & SEM & Mean & SEM & Mean & SEM & Mean & SEM & Mean & SEM \\
\hline $\mathrm{MCFA}+\mathrm{SC}\left(\mathrm{T}_{1}\right)$ & $42.000^{\mathrm{a}}$ & 0.949 & $47.800^{\mathrm{a}}$ & 0.663 & $11.800^{\mathrm{a}}$ & 0.663 & 46.000 & 0.707 & 2.120 & 0.080 \\
\hline $\operatorname{MCFA}\left(\mathrm{T}_{2}\right)$ & $38.300^{\mathrm{c}}$ & 0.539 & $42.300^{c}$ & 0.374 & $10.350 b^{c}$ & 0.430 & 46.250 & 0.592 & 2.106 & 0.065 \\
\hline $\mathrm{SC}\left(\mathrm{T}_{3}\right)$ & $40.150 \mathrm{a}^{\mathrm{b}}$ & 0.723 & $45.050^{\mathrm{b}}$ & 0.421 & $11.076^{\mathrm{a}}$ & 0.539 & 46.124 & 0.647 & 2.116 & 0.070 \\
\hline Control & $34.600^{\mathrm{b}}$ & 0.510 & $36.800^{d}$ & 0.860 & $8.900^{c}$ & 0.332 & 46.500 & 0.500 & 2.090 & 0.078 \\
\hline$P$ value & 0.000 & & 0.000 & & 0.006 & & 0.947 & & 0.992 & \\
\hline Significance level & $* *$ & & $* *$ & & $* *$ & & NS & & NS & \\
\hline
\end{tabular}




\begin{tabular}{l|c|c|c|c|c|c|c|c|c|c}
\hline & \multicolumn{2}{|c|}{ Pancreas } & \multicolumn{2}{c|}{ Proventriculus } & \multicolumn{2}{c|}{ Gizzard } & \multicolumn{2}{c|}{$\begin{array}{c}\text { Intestine with } \\
\text { chymus }\end{array}$} & $\begin{array}{c}\text { Intestine without } \\
\text { chymus }\end{array}$ \\
\cline { 2 - 12 } & Mean & SEM & Mean & SEM & Mean & SEM & Mean & SEM & Mean & SEM \\
\hline MCFA+SC $\left(\mathrm{T}_{1}\right)$ & 6.200 & 0.255 & $10.700^{\mathrm{a}}$ & 0.374 & $27.400^{\mathrm{a}}$ & 0.748 & $150.800^{\mathrm{a}}$ & 1.393 & $78.000^{\mathrm{a}}$ & 1.304 \\
MCFA $\left(\mathrm{T}_{2}\right)$ & 6.440 & 0.232 & $9.560^{\mathrm{b}}$ & 0.256 & $24.700^{\mathrm{b}}$ & 0.374 & $130.200^{\mathrm{c}}$ & 0.903 & $69.600^{\mathrm{c}}$ & 0.797 \\
SC $\left(\mathrm{T}_{3}\right)$ & 6.320 & 0.215 & $10.132^{\mathrm{ab}}$ & 0.310 & $26.050^{\mathrm{ab}}$ & 0.527 & $140.500^{\mathrm{b}}$ & 1.110 & $73.800^{\mathrm{b}}$ & 0.960 \\
Control & 6.680 & 0.384 & $8.420^{\mathrm{c}}$ & 0.208 & $22.000^{\mathrm{c}}$ & 0.548 & $109.600^{\mathrm{d}}$ & 0.927 & $61.200^{\mathrm{d}}$ & 1.241 \\
p value & 0.663 & & 0.000 & & 0.000 & & 0.000 & & 0.000 & \\
Significance level & $\mathrm{NS}$ & & $* *$ & & $* *$ & & $* *$ & & $* *$ & \\
\hline
\end{tabular}

Legends: MCFA= Medium chain fatty acids, $\mathrm{SC}=$ Saccharomyces cerevisiae

$*=$ Significant at $5 \%$ level of probability

** = Significant at $1 \%$ level of probability

NS $=$ Not significant

$\mathrm{SEM}=$ Standard error of mean in a column figures with same letter or without letter do not differ significantly whereas figures with dissimilar letter differ significantly (as per DMRT)
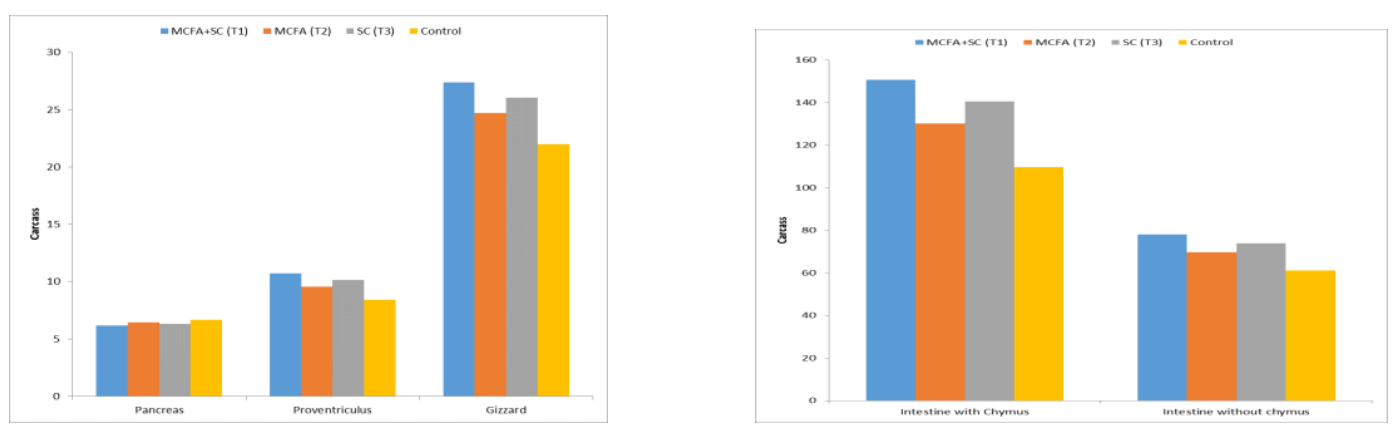

Figure 7. Carcass characteristics (Organ weights) Figure 8. Carcass characteristics (Organ weights)

\section{Cost- effectiveness of production}

It was obvious that medium chain fatty acids (galibiotic ${ }^{\circledR}$ ) and Saccharomyces cerevisiae type boulardii (Levucell SB 20 ME Powder ${ }^{\circledR}$ ) were effective on broiler production with a single using regimen more effective than combined one (Table 6 ).

Table 6. Cost effective analysis of different treatment groups of broilers fed on medium chain fatty acids (galibiotic $^{\circledR}$ ) and Saccharomyces cerevisiae type boulardii (Levucell SB 20 ME Powder ${ }^{\circledR}$ )

\begin{tabular}{lcccc}
\hline Description & $\mathrm{C}$ & $\mathrm{T}_{1}$ & $\mathrm{~T}_{2}$ & $\mathrm{~T}_{3}$ \\
\hline Cost/chick (Tk.) & 50 & 50 & 50 & 50 \\
Avg. feed consumed kg/birds & 2.175 & 2.169 & 2.164 & 2.160 \\
Feed price/kg (Tk.) $_{\text {Cost of Galibiotic }^{\circledR} \text { (Tk./bird) }}$ & 42 & 42 & 42 & 42 \\
Cost of Levucell SB 20 ME Powder $^{\circledR}$ (Tk./ bird) & 0 & 3.50 & 3.53 & 0 \\
Feed cost (Tk./ bird) & 0 & 3.68 & 0 & 3.60 \\
Miscellaneous (Tk./ bird) & 91.35 & 98.278 & 94.418 & 94.32 \\
Total cost/broiler (Tk.) & 18 & 18 & 18 & 18 \\
Average live weight (kg) & 109.35 & 116.278 & 112.418 & 112.32 \\
Sale price/Kg live wt. (Tk.) & 1.444 & 1.587 & 1.561 & 1.568 \\
Sale price/broiler (Tk.) & 124 & 124 & 124 & 124 \\
Net profit/broiler (Tk.) & 179.056 & 196.788 & 193.564 & 194.432 \\
Benefit over control/ broiler (Tk.) & 69.706 & 80.51 & 81.146 & 82.112 \\
\hline
\end{tabular}


Growth performance of broiler

\section{DISCUSSION}

This study was performed to assess the effects of dietary supplementation of medium chain fatty acids and Saccharomyces cerevisiae on growth performance of broiler chicks. Data analysis had shown that the average live weight gains were found always higher in MCFA+SC, MCFA and SC fed groups as compared to control group (1-28 days). According to Table 3 there were significant differences $(\mathrm{p}<0.01)$ among the MCFA+SC groups, MCFA groups and SC groups as compared to control groups. There were no significant differences between the MCFA and SC groups in weight gain trends. But there were significance difference $(p<0.01)$ between the MCFA+SC groups and control groups. In case of FCR, there was significant difference between control group and the treatment groups. But there was no significant difference within the $T_{1}, T_{2}$ and $T_{3}$ groups. This result is in agreement with the previously reported findings of several works. Higher body weight gains for MCFA and SC fed broilers were also reported by Kliseviciute et al. (2015), Hejdysz et al. (2012), Bradley et al. (1994), Zhang et al. (2005), Miazzo et al.(2005), Aghdamshahriar et al. (2005), Shareef and Al-Dabbagh (2009). Due to the higher production at low cost, best profit was observed in the group of birds fed Saccharomyces cerevisiae then control and other treatment groups. This was may be due to the effect of Saccharomyces cerevisiae in decreasing the harmful pathogen of the gut by inhibiting their attachment to the intestinal wall, as a result sound intestinal environment that causes more absorption of nutrients and improvement of the productive performances of broiler.

Data analyses of organ weight (Table 4) shows that the addition of MCFA and SC birds group ( $\left.\mathrm{T}_{1}\right)$ in diets of broiler chickens increased the weight of intestine with chymus by $41 \%(\mathrm{p}<0.01)$, intestine without chymus $17 \%(\mathrm{p}<0.01)$, gizzard 5\%(p<0.01), head 8\% $(\mathrm{p}<0.01)$, and neck $11 \%(\mathrm{p}<0.01))$ compared with control group ( C). But the birds group $\mathrm{T}_{1}, \mathrm{~T}_{2}, \mathrm{~T}_{3}$ and $\mathrm{C}$, weight of liver, spleen and pancreas showed no statistically significant difference. This result is in agreement with the previously reported findings of Kliseviciute et al. (2015).

\section{CONCLUSION}

The use of antibiotic growth promoter is increasing day by day. But their use in broilers is being banned due to some health hazard related issues. So it is high time, we explored the suitable alternatives of non-antibiotic growth promoter that does not affect the human health negatively. Therefore, the present study was intended to investigate the effect of feeding medium chain fatty acids and yeast (Saccharomyces cerevisiae type boulardii) that are non-antibiotic growth promoter on broiler performance. The supplementation of Medium chain fatty acids and yeast (Saccharomyces cerevisiae) at all level in broiler diets has improved the performance. These levels showed the best results on final body weight, live body weight gain, feed conversion, livability and organs weight. But best results were obtained by the combination of Medium chain fatty acids and yeast (Saccharomyces cerevisiae).The efficacy of medium chain fatty acids and Saccharomyces cerevisiae may have antimicrobial properties and it may be used as a non-antibiotic growth promoter because, the use of antibiotic growth promoter may create antibiotic resistant bacteria in the gastrointestinal tract and drug residuals in meat.

\section{REFERENCES}

1. Adebiyi OA, Makanjuola BA, Bankole TO and Adeyori AS (2012).Yeast culture (Saccharomyces cerevisiae) supplementation: effect on the performance and gut morphology of broiler birds. Global Journal of Science Frontier Research Biological Sciences 12:2249-4626.

2. Aghdamshahriar H, Nazer-adl K and Ahmadzadeh AR (2005).The effect of yeast (Saccharomyces cerevisiae) in replacement with fish meal and poultry by product protein in broiler diets. Worlds Poultry Science Association/WPSA-italy-2006/10390.

3. Akiba Y, Sato K and Takahashi K (2001). Meat color modification in broiler chickens by feeding yeast Phaffia rhodozyma containing high concentrations of astaxanthin. The Journal of Applied Poultry Research 10:154-161.

4. Ampel M, Mirsky N and Yannai S (2000). Prevention of lipid oxidation by glucose tolerance factor. Czech Journal of Food Sciences 18: 142-143.

5. Bonomi A, Bonomi BM, Quarantelli A and Orlandi A (1999). Organic chromium in the feeding of broiler chickens. Journal of the Food Science and Agriculture 28: 385-397. 


\section{Islam and others}

6. Bradley GL, Thomas FS and Karen IT (1994). The effects of supplementing diets with Saccharomyces cerevisiae var. boulardii on male poult performance and ileal morphology. Poultry Science 73: 1766-1770.

7. Hejdysz M, Wiąz M, Zefiak D and Rutkowski A (2012). Effect of medium chain fatty acids (MCFA) on growth performance and nutrient utilization in broiler chickens. Roczniki Naukowe Polskiego Towarzystwa Zootechnicznego 8: 9-17.

8. Khaksefidi A and Rahimi S (2005): Effect of probiotic inclusion in the diet of broiler chickens on performance, feed efficiency and carcass quality. Asian-Australasian Journal of Animal Sciences 18: 1153-1156.

9. Khosravinia H (2015). Effect of dietary supplementation of medium-chain fatty acids on growth performance and prevalence of carcass defects in broiler chickens raised in different stocking densities. The Journal of Applied Poultry Research 24: 1-9.

10. Kliseviciute V, Sasyte V, Gruzauskas R, Raceviciute-Stupeliene A, Slausgalvis V, Al-Saifi J and Pockevicius A (2015). Effects of dietary inclusion of medium chain $v$ fatty acids and butyrate on growth performance, organ weights, and intestinal histomorphology of broiler chickens. WPSA Proceeding/2015.

11. Lee J, Kim IYD, Kim DY, Choi YI, Ahn JN, Chae HS and Choi JH (2002). Effects of Saccharomyces cerevisiae on growth performance and meat quality of broiler chickens. Journal of Animal Production and Technology 1: 34.

12. Meyer AS, Karen R and Jens AN (1994). Critical assessment of the applicability of superoxide dismutase as an antioxidant in lipid foods. Food Chemistry 51: 171-175.

13. Miazzo RD, Mperalta F, Picco ML and Nilson AJ (2005). Productive parameters and carcass quality of broiler chickens fed yeast (S. cerevisiae). The XVIIth European Symposium on the Quality of Poultry Meat Doorwerth, the Netherlands.

14. Shareef AM and Al-Dabbagh ASA (2009). Effect of probiotic (Saccharomyces cerevisiae) on performance of broiler chicks. Iraqi Journal of Veterinary Sciences 23: 23-29.

15. Zhang AW, Lee BD, Lee KW, Song KB, An GH and Lee CH (2005). Effects of graded levels of dietary Saccharomyces cerevisiae on growth performance and meat quality in broiler chickens. Asian-Australian Journal of Animal Sciences 18: 699-703.

16. Zhang AW, Lee BD, Lee SK, Lee KW, An GH, Song KB and Lee CH (2005). Effects of yeast (Saccharomyces cerevisiae) cell components on growth performance, meat quality, and ileal mucosa development of broiler chicks. Asian-Australasian Journal of Animal Sciences 18: 699-703. 